\title{
Outro "mura", outros japoneses. Herança do Kasato-Maru
}

\author{
Other murá, other Japanese. The legacy of the Kasato-Maru
}

Isabel Mitsue Shimizu - Doutoranda em geografia, SET UMR 560. Université de Pau et des Pays de l'Adour. E-mail: isashimizu@gmail.com

\section{Resumo}

A comunidade nipo-brasileira comemorou em junho de 2008 o centenário da imigração; até hoje ela é a maior diáspora japonesa. Partindo de uma retrospectiva desse século de migração, o objetivo deste trabalho é mostrar, através de uma abordagem geográfica, formas de apropriação socioespaciais utilizadas pelos imigrantes japoneses para sua implantação no novo país, com destaque para o modo de inserção na Amazônia.

\begin{abstract}
The Nipo-Brazilian community celebrated in June 2008 the centenary of its inmigration to Brazil. Nowadays, it is the largest component of the Japanese diaspora in the world. Beginning with a retrospective on this immigration over a century, this paper takes a geographical approach in order to show what were the forms of socio-spatial appropriation which were used by Japanese immigrants for settling in their new land, with special emphasis on the way they integrated in Amazonia.
\end{abstract}

\section{Palavras-chave}

Imigração japonesa. Mura. Formas de habitar, Recomposição social e espacial.

\section{Keywords}

Japanese immigration. Mura. Ways of living; Social and spatial reorganization. 


\section{INTRODUÇÃO}

No contexto das migrações internacionais, a questão da relação do imigrante com o espaço e os habitantes do país hospedeiro está sempre presente (SANTOS, 2006). Através de uma abordagem geográfica, com ênfase às dinâmicas de inserção territorial, a contribuição deste trabalho tem o propósito de mostrar formas particulares de implantação e organização socioespaciais utilizadas pelos imigrantes japoneses no Brasil, consideradas como elementos reveladores da construção e concepção de espaços, no interior dos quais eles reproduzem formas de habitar, trabalhar e de se organizar socialmente, "especificamente japonesas". Essas configurações morfológicas e sociais particulares são remanescentes das formas conhecidas no Japão como muras (aldeias rurais), onde existe uma ligação intrínseca entre o habitante e o lugar. No Brasil, identificamos nas "colônias japonesas", que surgiram após a inserção de imigrantes japoneses nas fazendas de café, as mesmas características dos muras japoneses. O interesse desse trabalho não é o de retraçar a história da imigração, pois vários documentos já foram produzidos a respeito ${ }^{1}$, mas sim, de tentar, através da análise de dados históricos, identificar elementos particulares sobre o modo de organização social japonês, sua relação com o lugar, e procurar compreender as implicações desses elementos, como eles interagiram e interagem na construção ou na "deconstrução" da identidade da comunidade nipo-brasileira.

Através de uma breve retrospectiva à história do Japão, apresentaremos as origens do processo migratório ao Brasil, e algumas principais características do mura japonês, assim como o processo de sua transposição para o novo país, que é aqui percebida como uma estratégia de apropriação espacial utilizada pelos japoneses. Dentro das diferentes dinâmicas de implantação, destacamos o município de Tomé-Açu, considerado um caso particular na inserção dos japoneses na Amazônia, pela sua contribuição no desenvolvimento agrícola da região com a introdução do cultivo da pimenta-do-reino. Finalmente, a conclusão deste artigo seria uma reflexão sobre o futuro das comunidades nikkeis e a questão do retorno dos nipo-brasileiros ao país de origem.

Alguns documentos mais importantes produzidos sobre a imigração: Tomoo Handa (1987), Zenpati Ando (1976)

\section{ORIGENS DO PROCESSO MIGRATÓRIO}

Há mais de um século, iniciava-se no Japão uma campanha de emigração. Tratava-se de uma propaganda para incitar parte da população a emigrar para a América do Sul. Estratégia do governo japonês para controlar o excesso populacional, principalmente da população empobrecida? Desejo da parte dos governantes de colonizar terras de além-mar? De qualquer maneira, o processo de imigração dos japoneses teve início durante o período da chamada grande Restauração Social e Política da era Meiji, iniciada em 1867, e que correspondia ao fim do xogunato de Tokugawa ${ }^{2}$ e início da modernização do país (FUJIOKA, 1980, AKAMATSU, 1994), período pelo qual várias nações, incluindo o Japão, passavam por mudanças estruturais em consequência do processo da transição do regime feudal para um outro sistema. Entre outras consequências, verifica-se neste período a desintegração da classe de camponeses, que pela migração destes aos centros urbanos gera um aumento no índice de desemprego, contribuindo assim para o agravamento da crise socioeconômica. Foi nesse contexto que os primeiros emigrantes partiram ao Havai, para as ilhas Guam, em seguida aos Estados Unidos, México, e mais tarde à América do Sul. Por outro lado, nesta época, o Brasil tendo passado pela abolição da escravatura, necessitava de mão de obra laboriosa para as lavouras de café.

A primeira tentativa para viabilizar o início da imigração japonesa no Brasil data do final do século XIX, quando um acordo, Tratado de Amizade, Comércio e Navegação, foi assinado entre os dois países (CASTRO, 1979). Porém, em função de uma crise cafeeira ${ }^{3}$, superprodução e baixa de preço, este acordo foi suspenso. Com a persistência da crise, muitos imigrantes de origem europeia, principalmente italianos, começaram a abandonar as fazendas onde trabalhavam para irem se instalar nos subúrbios de São Paulo; muitos retornaram à Itália e outros se aventuraram partindo para Argentina. Este fato contribuiu para o agravamento da crise e o governo brasileiro elabora um plano para a introdução de novos imigrantes no país.

Em 1907, após outras frustradas tentativas, e a despeito das inquietações sobre o militarismo japonês a propósito da vitória na Guerra Russo-Japonesa, um

Os historiadores descrevem o xogunato de Tokugawa como sendo um período onde o sistema político feudal seu apogeu mais sofisticado.

Sobre o ciclo do café no Brasil, suas consequências, e sobre seu contexto regional, ver Monbeig (1984), Ando (1976), Droulers (2001) e Claval (2004). 
acordo foi firmado entre a Companhia Imperial de Imigração Tókio-Japão e o governo do estado de São Paulo (SHINDO, 1999). Pouco tempo depois, em junho de 1908, atracava no porto de Santos o Kasato-Maru, navio japonês procedente do porto de Kobe, no Japão, que trazia como passageiros os primeiros imigrantes japoneses em escala representativa - 165 famílias, num total de 733 pessoas, que chegavam ao Brasil em busca de uma terra para melhorar suas condições de vida, e também, porque não dizer, na esperança de encontrar um novo lugar que desse sentido às suas vidas. Apesar de não existir mais, pois foi bombardeado e afundado durante a Segunda Guerra mundial, a imagem do navio Kasato-Maru resta como símbolo do início da imigração japonesa no Brasil. Atualmente, os japoneses e descendentes que vivem fora do Japão são chamados de nikkei e são estimados em aproximadamente 1,5 milhões de habitantes. Uma terminologia nominativa os distinguem segundo a geração a qual eles pertencem, assim os issei $(i=$ prefixo do número 1 , e sei = geração) constituem os imigrantes que nasceram no Japão, os nissei constituem a segunda geração, sansei terceira geração, yonsei, a quarta geração, e assim sucessivamente.

\section{INÍCIO DA IMPLANTAÇÃO SOCIOESPACIAL}

Os primeiros imigrantes japoneses que chegaram ao Brasil foram distribuídos em seis fazendas de café no estado de São Paulo (HANDA, 1987). Em todas as propriedades, as instalações destinadas aos imigrantes eram semelhantes e se resumiam a uma concentração de casas enfileiradas, bastante simples, sem nenhuma mobília, variando apenas de tamanho, pois algumas eram destinadas a abrigar até três famílias debaixo do mesmo teto. Provavelmente, os imigrantes sentiram falta dos tatames japoneses, pois não havia camas nas casas e frequentemente o chão era de terra batida. Os principais problemas, além das más instalações, eram os atritos com os administradores, cafeeiros velhos que comprometiam a colheita, trabalho sob fiscalização de capatazes. O mais grave, porém, era referente à remuneração, devido principalmente à crise cafeeira; o ganho não correspondia ao que anunciava a companhia de imigração. Rapidamente os imigrantes japoneses se conscientizam de que ao invés de chegar ao "Eldorado", eles se encontravam era num verdadeiro "inferno vivo" (SHINDO, 1999).

Se a fase inicial foi marcada por momentos penosos, por outro lado, ela teve também momentos de descobertas, de exploração de uma nova terra, de um novo espaço que ia se transformar sem que eles imaginassem, no futuro lugar de existência. Com certeza, inicialmente, esse lugar existencial ficou no passado, num outro país. Partir, significa, antes de tudo, abandonar as atividades econômicas, políticas e tradicionais da sociedade de origem; significa deixar o sistema de referência espacial e temporal que une e situa cada indivíduo dentro de uma sociedade. Desse modo, a vida social de um indivíduo ou de um grupo inteiro se encontra desorientada. Lembrando as palavras de Santos (2006, p. 222) "Quando o homem se defronta com um espaço que não ajudou a criar, cuja história desconhece, cuja memória lhe é estranha, esse lugar é a sede de uma vigorosa alienação". É um momento de alienação, pois ele não está mais no seu país de origem e conhece muito pouco sobre o novo lugar... Entretanto, temos que levar em consideração que o novo habitat incita também a novas experiências, a repensar a ideia do futuro a partir da observação e compreensão do novo meio onde ele se encontra, baseando-se em experiências deixadas para trás.

Ainda segundo Santos (2006, p. 224),

"a memória olha para o passado. A nova consciência olha para o futuro. O espaço é um dado fundamental nessa descoberta. Ele é o teatro dessa nova ação por ser, ao mesmo tempo, futuro imediato e passado imediato, um presente ao mesmo tempo concluído e inconcluso, num processo sempre renovado. Quanto mais instável e empreendedor for o espaço, tanto mais surpreendido será o indivíduo e tanto mais eficaz a operação da descoberta. A consciência pelo lugar se superpõe à consciência no lugar. A noção de espaço desconhecido perde a conotação negativa e ganha um acento positivo, que vem do seu papel na produção da nova história" (SANTOS, 2006, p. 224).

Quais foram as estratégias adotadas pelos Japoneses no seu processo de implantação?

Passado o período de perplexidade, os imigrantes instalados nas fazendas se conscientizam rapidamente que é preciso encontrar um meio para saírem dessa situação de semi-escravidão (ANDO, 1976). Muitos se transferem para outras fazendas, alguns fogem para tentarem a sorte nas cidades. Para se ter uma ideia, dos 773 japoneses enviados às fazendas, 430 haviam se retirado depois de seis meses. Não seria possível descrever aqui toda a saga vivida pelos imigrantes japoneses, mas existem vários trabalhos publicados sobre o assunto. Um dos documentos mais completos sobre a história da imigração japonesa é o de Tomoo Handa (1987).

Os imigrantes japoneses que deixam as fazendas, seja porque chegam ao final do contrato, seja porque conseguem fugir das fazendas, começam a se concentrar em pequenos núcleos coloniais onde se organizam e recompõem modelos e formas 
de habitar existentes no seu país de origem. Esses modelos correspondem aos muras japoneses, que no Brasil detectamos como sendo as "colônias Japonesas". Parece-me oportuno fazer aqui um pequeno resumo sobre esse modelo particular.

\section{REPRESENTAÇÃO DO MURA}

O mura é uma forma de organização socioespacial que provém do meio rural do Japão. Provavelmente foi consolidada no período do isolacionismo, que precede o da emigração ao Brasil, como meio de impedir a intromissão de estrangeiros e ao mesmo tempo manter o poder dos senhores feudais. Não deixa de ser uma forma de habitar muito antiga e fundamental na cultura rural japonesa. $\mathrm{O}$ mura equivale a uma representação de ordem socioespacial onde é eleito numa assembleia anual o sonchô, chefe da aldeia, e abaixo dele são eleitos outros representantes para cargos de subdireção para tratar de assuntos de interesse coletivo, como educação, assuntos financeiros, culturais, produção agrícola etc. Nesses muras existem também regras a respeitar e os que as infringem estão sujeitos a penalidades, como a exclusão do infrator da aldeia. O conceito de mura vai além de um núcleo estrutural constituído pelas infraestruturas materiais e espaciais com funções sociais e administrativas; ele implica também uma ligação sentimental muito forte, pois é igualmente o lugar onde viveram os antepassados. Desse modo, há uma ligação indissociável entre o habitante e o lugar. Essa ligação é fundamental. Assim, o mura teria servido de base para a construção da personalidade individual, da mesma maneira que podemos considerar que no campo da geografia o sujeito e o lugar são co-construídos (BERDOULAY; ENTRIKIN, 1998). Talvez esta seja uma das razões para explicar porque certos grupos minoritários que até hoje são discriminados no Japão como os Burakumin, mesmo que queiram, no momento de procurar trabalho ou casamento, por exemplo, muitas vezes não conseguem ocultar suas origens ${ }^{4}$.

Existem indícios da existência de formas rudimentares de mura desde o século III, mas segundo Ryuziro (1969) as primeiras formas de mura no Japão datam do século VIII. Essa configuração social e espacial se reforça durante o sistema feudal japonês, onde a família administrava e gerava um espaço com fins agrícolas, sociais e culturais. Um mura japonês é formado por 30 a 80 pequenos

4 Os Burakumin ou Etas são os párias no Japão. Atualmente eles totalizam 3 milhões de pessoas, e apesar de uma lei surgida em 1871 que abolia o status oficial de Burakumin e os renomeava Shin heimin (pessoas novas comuns), eles continuam a viver em guetos e a sofrer discriminação. (ver SABOURET, 1983, De VOS; WAGATSUMO, 1966). povoados nomeados de buraku e cada um desses povoados pode conter cerca de 100 casas. Esses povoados constituem a unidade mais elementar da vida rural. Tudo o que concerne à vida agrícola deve passar pelo mura.

Distingue-se basicamente quatro tipos de estruturas diferentes de mura, segundo a morfologia espacial, período de formação e interesses políticos. O tipo jôri apresenta forma geométrica quadricular. O tipo goshi (gố: país, shi: samurai) teve iniciativa pelos senhores feudais na idade média e mais aparece renovado pelos samurais, que eram ao mesmo tempo proprietários de terras e oficiais militares; eles residiam no centro da aldeia e os camponeses na periferia. O tipo shinden (shin: novo, den: rizicultura) aparece no período do xogunato de Tokugawa; surgiu como uma estratégia dos senhores feudais que tinham necessidade de aumentar a coleta de impostos para poderem manter suas vidas luxuosas nas cidades. Finalmente, o tipo tonden-hei (ton: ficar para defender, den: rizicultura, hei: soldado) aparece em 1875, na ilha de Hokaido, e corresponde à primeira frente pioneira na ilha, considerando a dificuldade de acesso à densa floresta. Após a Restauração de Meiji, o governo supeitando de invasão russa no território envia soldados para desmatar a floresta a fim de permitir a implantação das aldeias rurais. Foi assim que a maior parte da região setentrional do país foi ocupada (BERQUE, 1980).

Assim, o surgimento do mura no Japão foi uma forma estratégica de defesa contra a invasão de estrangeiros e manutenção do poder dos senhores feudais, ao mesmo tempo ele era uma estrutura que servia para organizar a colonização de novos espaços agrícolas. Forma ao mesmo tempo espacial e social, ela condicionou a visão do mundo dos trabalhadores rurais no Japão. Foi essa forma de organização socioespacial que serviu como referência à implantação dos japoneses no Brasil, a exemplo do que já aconteceu no passado com os imigrantes na Manchúria e na colonização de Hokaido (ONO, 1966).

\section{DE UM MURA A OUTRO: TRANSIÇÃO ESPACIAL E SOCIAL}

O mura, como foi mencionado acima, também é encontrado no Brasil. Essa forma de habitar pode existir frequentemente nas chamadas "colônias japonesas". Identificamos no Brasil o termo colônia, como uma expressão mais genérica utilizada para designar um agrupamento de habitantes com características comuns, e não necessariamente a forma de organização socioespacial desses habitantes. A palavra colônia pode ser entendida de duas formas - a primeira refere-se ao 
termo como designação geral de comunidades estrangeiras estabelecidas no Brasil, e, a segunda, como indicativo de determinada localidade onde se concentram colonizadores japoneses e se constitui em uma comunidade regional exclusiva de japoneses e que corresponderia ao mura.

Nessa última forma, ela pode agrupar várias vilas rurais (ou buraku) e nesse caso cada vila se torna um bairro na colônia. Esse agrupamento se constrói segundo critérios variados, como, por exemplo, o lugar de origem do Japão, se são recémchegados ou se já estão há algum tempo, ainda um nome ligado a um evento ou uma história. Os imigrantes não se instalam ao acaso mas se estabelecem num determinado lugar em função de critérios particulares. Por exemplo, as pessoas originárias de Okinawa se reagrupam num determinado lugar e vão se distribuir em várias colônias habitadas essencialmente de Okinawanos.

Podemos dizer que o processo inicial que impulsionou os japoneses à formação das colônias foi, de um certo modo, o resultado do descontentamento dos imigrantes face às difíceis condições de vida nas fazendas, e a conscientização de que o objetivo inicial de ganhar dinheiro rapidamente e retornar ao Japão com os bolsos cheios, era um sonho cada vez mais distante da realidade.

Como acontece o surgimento das colônias japonesas no Brasil? Observamse cinco diferentes tipos de formação de núcleos coloniais (SOCIEDADE BRASILEIRA DE CULTURA JAPONESA ,1992; SAITO, 1973). O primeiro tipo ocorre pelo agrupamento espontâneo de um pequeno número de imigrantes num determinado lugar; o critério para formação desse grupo pode variar, como já foi mencionado acima, pelo ano de chegada, lugar de origem, parentesco etc. Com o aumento de imigrantes que se instalam ao redor, forma-se uma concentração de proporções consideráveis, logo se forma uma associação e está caracterizada o aparecimento de uma colônia. Os primeiros núcleos de colonização de imigrantes japoneses no Brasil surgem a partir de 1910. Eles são formados pela iniciativa dos próprios imigrantes, com a liderança de um chefe.

O segundo tipo são as colônias, ou shokuminchi, em japonês, constituídas pela aquisição de lotes de terras vendidas pelos emigrantes pioneiros. Como descreve Ono (1996), quando glebas são divididas em pequenas áreas de 10 a 20 hectares e os imigrantes japoneses nelas se introduzem sob um plano previamente traçado, as colônias assim construídas reproduzem a mesma estrutura espacial e social do próprio mura do Japão. Este tipo de formação foi a mais frequente no estado de São Paulo e norte do Paraná. Temos aqui o exemplo de Assaí, no norte do Paraná (YASARI, 1992), onde cada seção representa um mura (Figura 1).

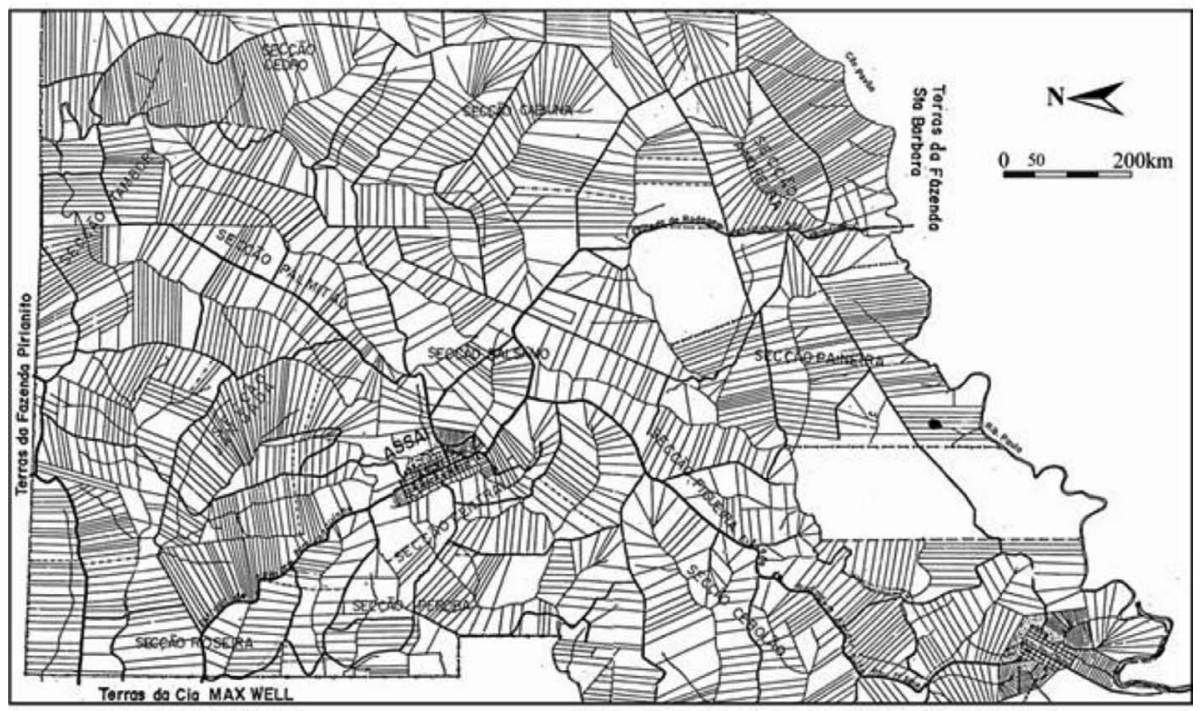

Figura 1. Planta parcial da Fazenda Três Barras - Município de Assaí, 1942. Fonte: A. Asari, 1992

No terceiro caso, a formação ocorre através de capital privado do Japão, que adquire terras ou recebe em concessão sem ônus terras devolutas. As terras são loteadas; os colonizadores podem ser antigos imigrantes residentes no país. Neste caso as colônias recebem a denominação de shokuminchi como no segundo caso, ou então por colonos que adquirem os lotes no Japão e emigram depois; essas colônias são chamadas de $i j \hat{u}$-chi (terra para onde se migrou). A distinção aqui não se restringe apenas à nomeação, mas também à mentalidade. Eles se sentem superiores, pois têm o apoio do governo. A primeira colônia deste tipo surgiu em 1913, na realidade um conjunto de três colônias e, como todas ficavam à margem do rio Ribeira de Iguape, ficou conhecida como Colônia Iguape. Ela foi fundada com capital privado nipônico, por Ikutaro Aoyagi, representante da Tokyo Syndicate que conforme acordo com o governo paulista recebeu terras de propriedade do Estado. Outro exemplo que cabe citar aqui é a comunidade de Três Alianças, no município de Mirandópolis, no interior do estado de São Paulo, onde cada uma das Alianças representa um mura (Figura 2).

Outra forma descrita, que talvez não possa ser chamada de colônia, acontece em época de prosperidade da cotonicultura e concentravam japoneses arrendatários para o cultivo do algodão. Chegava-se a formar escolas e associações, mas como eles não eram proprietários, estas aglomerações desapareciam depois de um certo tempo. 


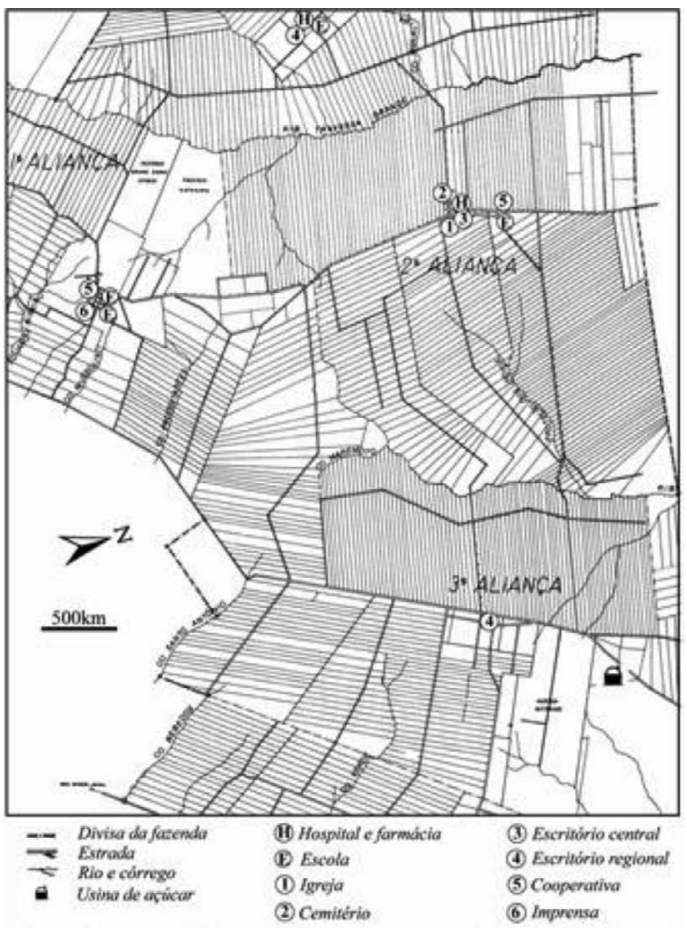

Figura 2. Planta parcial da Fazenda Aliança - Município de Mirandópolis, 1938. Fonte: R. Yoshioka, 1995

O quinto tipo consiste na formação de colônias nos núcleos coloniais oficiais do governo estadual. Temos colônias que surgiram no estado de São Paulo antes da Segunda Guerra, e no pós-guerra, em outros estados como Bahia, Mato Grosso e região amazônica. Aqui temos como exemplo o município de Tomé-Açu (Figura 3).

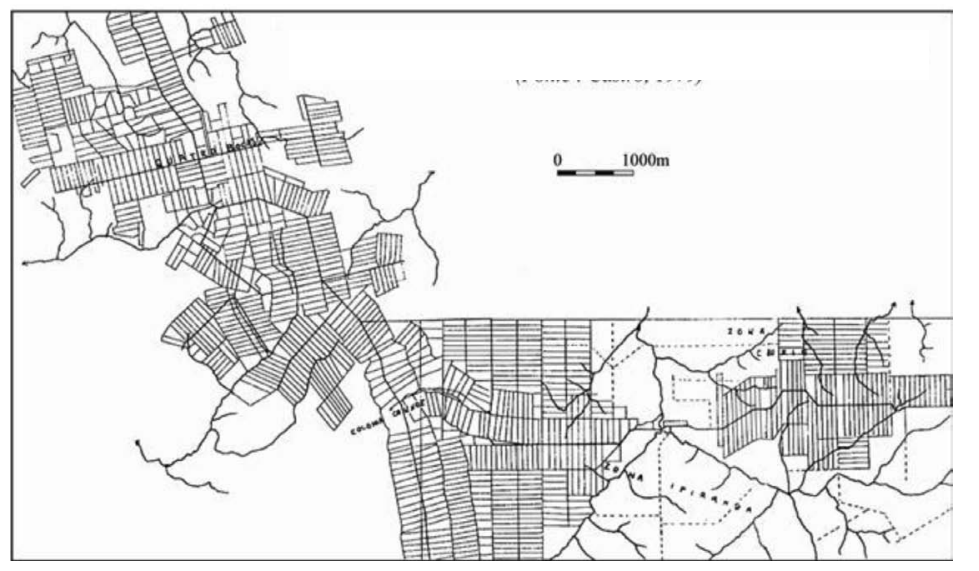

Figura 3. Planta parcial da localização da colônia - Município de Tomé Fonte: Castro, 1979
Nas colônias japonesas, nota-se também o aparecimento das cooperativas (SAITO, 1965). De um lado, a criação das cooperativas funciona como uma estratégia para evitar intermediários no escoamento dos produtos, mas, por outro lado, para os Japoneses, ela fortalece as relações sociais existentes nas colônias entre os associados. O mura, devido à forte coesão social ao qual ele induz, agiu como um modelo de funcionamento no estabelecimento e difusão das cooperativas no Brasil. A primeira cooperativa agrícola formada pelos japoneses que se tem conhecimento data de 1919, na região de conquista em Minas Gerais (ANDÔ, 1959); a mais conhecida no Brasil foi a Cooperativa Agrícola de Cotia.

As colônias e cooperativas japonesas se prevaleceram certamente do "espírito do mura" que persiste no Brasil, mesmo se suas formas espaciais não corresponderam exatamente às formas originais encontradas no Japão. Contudo, devemos nos questionar sobre algumas tensões que afetaram esse modelo e quais as consequências no processo de integração no Brasil.

\section{TENSÕES IDENTITÁRIAS}

De um lado, as colônias favoreceram a instalação dos japoneses, que aqui encontraram ou criaram uma organização socioespacial inspirada no mura. De outro lado, eles utilizaram as práticas sociais existentes nessas organizações para garantirem a coesão de um grupo e é conhecido que eles utilizam frequentemente as redes sociais como modo de se fortalecerem enquanto comunidade minoritária. Nesse caso, houve simplesmente uma mudança na escala da organização socioespacial, mas a dinâmica permaneceu a mesma. Isso se verifica, aliás, nas cidades: mesmo que minoritários, os japoneses criaram associações seguindo as mesmas lógicas de integração do grupo com as mesmas barreiras e rituais que observamos no meio rural.

Todavia, esse processo nem sempre ocorreu livre de conflitos. No que se refere às relações entre os japoneses, um dos fatos mais marcantes, que gerou tensões e mortes de imigrantes japoneses, ocorreu após a segunda guerra, com o surgimento da organização Shindo Renmei ${ }^{5}$. O movimento se caracteriza por graves conflitos entre os "derrotistas" e "vitoristas", ou seja, os que não acreditavam na derrota do Japão na Segunda Guerra contra aqueles que acreditavam (MORAIS, 2000).

Outra questão, de complexidade talvez difícil de ser identificada e visualizada, pois seu efeito às vezes repercute somente ao longo do tempo, diz respeito às relações de hierarquia que surgiram entre os japoneses mais velhos, os

\footnotetext{
Liga do Caminho dos Súditos, foi uma organização secreta que surgiu em 1946 e que separou os imigrantes japoneses em dois grupos: o dos "vitoristas", que acreditavam na vitória do Japão, e o dos "derrotistas", que acreditavam na derrota dos japoneses na Segunda Guerra.
} 
isseis (de primeira geração) e os nisseis (segunda geração). No Brasil, a maioria dos nipo-brasileiros são conhecidos pelo temperamento dócil, pacatos, honestos e trabalhadores. Observando os escritos de Handa (1987) sobre a personalidade dos nisseis que viviam nos núcleos coloniais no período anterior à segunda guerra, observamos que ele descreve com muita sensibilidade a situação vivida pelos descendentes dos imigrantes. Frequentemente havia uma certa recriminação, por parte dos mais velhos, aos nisseis que por não terem tido condições de se formarem, por força das circunstâncias, nem culturalmente e nem linguisticamente, eram discriminados. Essa discriminação, entretanto, não era um empecilho para os isseis, de valorizarem a educação, pois desde a existência dos primeiros núcleos coloniais sempre houve a preocupação de se construírem escolas. A questão era que a forma de ensino praticada não era adaptada aos descendentes; não existia uma metodologia pedagógica que atraísse a atenção de crianças que conheciam o Japão somente através das histórias que os pais contavam, lembrando-se que na época não havia uma preocupação, nem condições para se dar aos descendentes uma educação com bases psicológicas adequadas.

A reflexão que faço aqui é que a pressão exercida pelos mais velhos aos mais jovens, não teria contribuído para moldar a personalidade desses descendentes que não compreendiam perfeitamente a língua materna e que também não dominavam perfeitamente o português, se encontrando, assim, sem estrutura para se autoafirmarem. Estavam num novo país com costumes totalmente diferentes, mas tinham que viver segundo os princípios japoneses. Em resumo, não conheciam muito bem nenhuma das duas culturas; para os mais velhos eles eram "incapazes", a começar pelo domínio da língua; não tinham a vivacidade que tinham os jovens imigrantes japoneses recém-chegados, como descreve Handa. Uma distância cultural agravada pela distância de gerações?

Com o fenômeno dos dekassegui ${ }^{6}$, muito se fala a respeito da questão identitária dos nipo-brasileiros (SAKURAI, 2002; SASAKI, 1995): no Japão eles não são considerados como japoneses e no Brasil eles não são inteiramente brasileiros. Esse problema talvez tenha tido suas origens muito antes dos nikkeis se confrontarem com uma situação de reencontro com as raízes de seus ancestrais, onde eles se conscientizam de que não são considerados como Japoneses, pois me parece que há uma repetição dos problemas identitários, não somente com os próprios dekasseguis, mas também com os seus descendentes.

Sendo assim, a história parece se repetir - o mura japonês no Brasil foi em parte bem-sucedido, mas deixou sequelas difíceis de serem resolvidas do ponto de vista de formação psicológica e identitária dos descendentes. Essa questão

\footnotetext{
Nikkeis que retornam ao Japão para trabalhar.
}

continua existindo, agora com o agrupamento de brasileiros no Japão formando novos muras: processo inverso, mesmos problemas?

\section{PARTICULARIDADES DA IMPLANTAÇÃO NA AMAZÔNIA}

A chegada dos Japoneses na Amazônia ocorre tardiamente, em 1929, e seu processo de implantação apresenta peculiaridades interessantes em relação à instalação dos imigrantes do sul. Mesmo se a população não ultrapassa os 54.000 habitantes ${ }^{7}$, o processo de implantação adquiriu características suficientemente similares para conduzir à emergência de particularidades regionais.

A maior concentração começou no Pará, em Acará, atual Tomé-Açu, que acabou se tornando símbolo da colonização nipônica na Amazônia, pelo seu sucesso no cultivo da pimenta-do-reino. A colonização de Tomé-Açu, como ocorreu em algumas outras colônias, foi previamente planificada, seguindo o concepção e os princípios japoneses do mura. A maioria dos imigrantes pertenciam a uma classe financeira mais favorecida que os pioneiros do sul; muitos vinham já com os lotes de terras adquiridos anteriormente, tendo em vista a concessão de uma grande superfície de terras efetuadas, principalmente pelos governos do Pará e do Amazonas. Apesar de terem sido hostilizados pelos compatriotas do sul, que os apelidaram de "imigrantes de estufa" (TSUNODA, 1988), pois achavam que estes privilegiavam de melhores condições, eles enfrentam muitos problemas até conseguirem se estabelecer. A selva amazônica era um meio totalmente desconhecido e representava um verdadeiro "inferno verde", com riscos de contraírem doenças endêmicas como a malária, por exemplo. A despeito de todas as barreiras, várias experiências japonesas tiveram sucesso, como por exemplo a introdução do cultivo da juta e malva nas várzeas amazônicas (HOMMA, 2007).

Uma das particularidades da imigração na Amazônia reside no fato de que eles não passaram pela experiência do trabalho nas fazendas de café. Outro fator interessante, relacionado ao anterior, foi que, apesar de muitos terem ido tentar a sorte no sul, devido às condições inóspitas do lugar, os que restaram permaneceram no local e souberam inovar, introduzindo outros tipos de culturas, ao contrário dos imigrantes do sul, onde houve um alto índice de mobilidade. A implantação na Amazônia adquiriu, assim, um enraizamento que não foi a característica dominante da experiência japonesa no sul.

A especificidade amazônica é assim reforçada pela introdução de novas produções agrícolas nessa região. Em Tomé-Açu, a atividade agrícola planejada no início era o cultivo de arroz e cacau, mas, como não houve êxito, resolveram

Fonte IBGE microdados dos censos 1980, 1981, 2000. 
experimentar o cultivo da pimenta-do-reino, cujo sucesso levou o estado do Pará a exportar o produto. Pode-se dizer que o sucesso foi em grande parte atribuído ao modo de organização dos japoneses através do cooperativismo que provém das formas de organização espacial e social relacionadas ao mura. Além das culturas citadas anteriormente, os japoneses também introduziram na Amazônia várias espécies frutíferas como o mangostão e o rambotã. Assim, os Japoneses através de sua contribuição, principalmente no setor agrícola, fazem parte da história da agricultura amazônica (ibid.). Embora pouco numerosos e ainda fortemente dependentes do espírito do mura, como ainda ocorre em outros lugares no resto do país, a população japonesa da Amazônia adquiriu características regionais próprias, contribuindo à distinção de uma região no interior do Brasil.

\section{CONCLUSÃO}

Dentro do contexto econômico-social, pode-se dizer que os imigrantes japoneses superaram as duras adversidades que sempre existem em migrações forçadas, seja por razões econômicas, sociais ou políticas, com bastante êxito. Eles souberam utilizar formas socioespaciais que funcionaram bem no país, ou melhor, eles fizeram com que esses modelos funcionassem bem. Nesse processo, o mura teve um papel fundamental, pois ele inspirou a organização socioespacial dos japoneses no Brasil. No período de um século, os imigrantes, vindos do outro lado do planeta conquistaram seu espaço no novo país e, rapidamente, adquiriram também ascensão social, fruto de investimentos na educação (MAEYAMA, 1970).

As condições da chegada no Brasil e as particularidades do meio local foram combinadas para fazer emergir uma configuração regional particular na região amazônica. Mesmo se a maior parte da população de origem japonesa vive e trabalha no sul, a pequena população instalada na Amazônia desenvolveu uma experiência diferente, ao mesmo tempo que ela contribuiu para a originalidade desse vasto espaço regional no interior do Brasil.

Atualmente, com o retorno dos dekassegui à terra de origem, várias questões se apresentam com relação aos nipo-brasileiros, questões identitárias, sociais etc. Porém, se fizermos uma análise retrospectiva à história da imigração, detectaremos que os japoneses reproduziram muito bem os modelos socioespaciais do Japão. Porém, talvez na preocupação de "vencer na vida", não tiveram tempo de se preocupar com aspectos mais profundos da implantação, não somente, por exemplo, enviar os filhos à escola para poderem atingir uma ascensão social, mas dar mais atenção à questão identitária no sentido de se valorizarem enquanto conhecedores de duas culturas diferentes. Pois, os nikkeis brasileiros não são mais os mesmos japoneses que chegaram ao Brasil há um século, e tampouco se identificam com os japoneses do Japão. Paradoxalmente não seria o mura, tal como foi adaptado pelos nikkeis no Brasil e reintroduzido em sua nova forma, a chave das forças e das dificuldades da classe minoritária "brasileira" no Japão?

\section{REFERÊNCIAS}

AKAMATSU, P. Le Japon sous le Tokugawa. Historiens Géographes, n. 344, p. 163-180, 1994.

ANDÔ, Z. Cotia Sangyô Kumiai Sanju-nen no Ayumi. São Paulo: Cooperativa Agrícola de Cotia, 1959.

ANDÔ, Z. Estudos Sócio-Históricos da Imigração Japonesa. São Paulo: Centro de Estudos Nipo-Brasileiros, 1976.

BERDOULAY, V.; ENTRIKIN, J. N. Lieu et sujet. Perspectives théoriques. L'Espace géographique, v. 27, n. 2, p.75-89, 1998.

BERQUE, A. La rizière et la banquise, colonisation et changement culturel à Hokkaido. Paris: Publications Orientalistes de France,1980.

CASTRO, F. M. Cinqüenta anos de Imigração Japonesa na Amazônia. Belém: [s.n.], 1979.

CLAVAL, P. La Fabrication du Brésil, une grande puissance en devenir. Paris: Belin, 2004.

DEVOS, G.; WAGATSUMO, H. Japan's Invisible Race: Caste in Culture and Personality. Berkeley: University of California Press, 1966.

DROULERS, M. Brésil: une géohistoire. Paris: PUF, 2001.

FUJIOKA, K. The changing face of Japanese jokamachi (castles towns) since the meiji period. In: Geography of Japan. Tokyo : Teikoku-Shoin, 1980. p.146-160.

HANDA, T. O Imigrante Japonês. História de sua vida no Brasil. São Paulo: T.A. Queiróz, 1987.

ISIDA, R. Geography of Japan. Tokyo: Kokusai Bunka Shinkokai, 1969.

MAEYAMA, T. Religião, Parentesco e as classes medias dos japoneses no Brasil Urbano. In: Estudos Brasileiros, Assimilação e Integração dos Japoneses no Brasil. São Paulo: Vozes, 1970. 
MONBEIG, P. Pioneiros e Fazendeiros de São Paulo. São Paulo: Polis, 1984. MORAIS, F. Corações sujos. A história da Shindo Reimei. São Paulo: Companhia das Letras, 2000.

ÔNO, M. De colono a pequeno produtor. In: HIROSHI, S.; MAEYAMA, T. (Coords.). Assimilação e Integração dos Japoneses no Brasil. São Paulo: Vozes, 1966. p. 129-163.

SABOURET, J-F. L'autre Japon, les Burakumin. Paris: La Découverte-Maspero, 1983.

SAITO, H. Comunidade Rural. Estudos Brasileiros, Assimilação e Integração dos Japoneses no Brasil. São Paulo: Vozes, 1965.

SAITO, H.; TAKASHI, M. (Orgs.). Estudos Brasileiros, Assimilação e Integração dos Japoneses no Brasil. São Paulo: Vozes, 1970.

SAKURAI, C. Mais estrangeiro que os outros. Travessia Revista do migrante, n.44, 2002.

SANTOS, M. A Natureza do espaço, Técnica e Tempo, Razão e Emoção. 4. ed. São Paulo: Edusp, 2006.

SASAKI, E. M. Dekasseguis, trabalhadores nipo-brasileiros no Japão. Travessia Revista do migrante, n. 25, 1995.

SHINDO, T. Brasil e Japão, os 100 anos de Tratado de Amizade. São Paulo: Associação Cultural Recreativa Akita Kenjin do Brasil, 1999.

SOCIEDADE BRASILEIRA DE CULTURA JAPONESA. Uma Epopéia Moderna, 80 anos da Imigração Japonesa no Brasil. São Paulo: Hucitec, 1992. THÉRY, H. Le Brésil. Paris: Masson,1995.

TSUNODA, F. Canção da Amazônia: uma saga na selva. Rio de Janeiro: Francisco Alves. 1980.

YASARI, A. Y. E eu só queria voltar ao Japão. Colonos japoneses em Assaí. 1992. Dissertação (Mestrado) - Departamento de Geografia/FFLC, Universidade de são Paulo, São Paulo, 1992.

YOSHIOKA, R. Por que Migramos do e para o Japão. São Paulo: Massao Ohno, 1995.

Texto submetido à Revista em 14.5.2010

Aceito para publicação em 3.7.2010 